\title{
Residential Characteristics of Armed-Forces Personnel and the Urban Economy: Evidence from a Medium Sized City in Greece
}

Dimitrios Skouras ${ }^{\dagger}$ Paschalis A. Arvanitidis, Christos Kollias*

\section{Abstract:}

The paper explores the locational and residential decisions of Greek military households. To achieve this, primary data were collected by means of a questionnaire survey addressed to military personnel located in Volos, a medium-sized Greek city in the greater area of which a number of major military facilities are located. The study starts by examining the residential distribution of military households to consider whether clustering or dispersion is evident. Then, an attempt is made to explain the observed pattern with reference to conventional urban economics' determinants of location choice or to other factors related to the social or professional characteristics of the group. Such analysis enables us to draw some preliminary conclusions on the potential effects military facilities have on both the urban spatial structure and the housing market.

Keywords: military households, urban location, housing, Greece

JEL: D12, H56, J15, R23, R31

DOI: $10.2478 / \mathrm{v} 10033-012-0008-4$

\section{Introduction}

A plethora of links connect directly or indirectly the economy and the defence sector. This relationship has attracted considerable attention, giving rise to a large and growing amount of both theoretical and empirical studies investigating various aspects of it (see Hartley and Sandler 1990 1995, Brauer and Hartley 2000, Brauer and Dunne 2002, Sandler and Hartley 2007). A number of recent studies, departing from the dominant focus on the relationship between defence and the economy on the national level, have addressed the issue of the impact of the defence sector on the regional economy level (see Braddon 1995, Hooker and Knetter 2001, Poppert and Herzog 2003, Andersson, Lundberg, and Sjostrom 2007, Asteris et al. 2007). At its simplest, military camps and bases need goods, services and labour for their operation, most of which are usually drawn from local markets. In addition, employed personnel, and their families, reside and consume in the urban area close to where military

\footnotetext{
* We like to dedicate this paper to the memory of our co-author, Dimitrios. Major Dimitrios Skouras was killed during a night exercise on November 5th, 2008 when his Apache helicopter crashed.
}

facilities locate, exerting an influence on both its economy and its spatial structure.

In this context, the current study attempts to investigate some of these regional side-effects of the defence sector. In particular, drawing on a questionnaire survey, it explores the residential characteristics of Armed-Forces Personnel (henceforth AFP) households, using Volos - a medium-sized Greek city with a population around 130,000, hosting major military facilities, including an air force base and a marine unit - as

* Dimitrios Skouras ${ }^{\dagger}$

Hellenic Army Aviation Corps \& Department of Regional Planning and Development, University of Thessaly, Greece

Paschalis A. Arvanitidis (corresponding author) Department of Economics, University of Thessaly, Greece

E-mail: parvanit@uth.gr

\section{Christos Kollias}

Department of Economics, University of Thessaly, Greece 
a case study. More specifically, the paper first examines the intra-urban locational distribution of the AFP households to consider whether clustering or dispersion is evident and then analyses their housing attributes to assess whether they are affected by economic or by social factors. Such analysis enables us to draw some preliminary conclusions on the potential effects military facilities have on both the urban spatial structure and the housing market. In doing so, the paper is structured as follows. The next section outlines the approaches that have been developed to explain households' residential decisions and location choices. Following this, the methodology, data and empirical findings are presented and discussed in section three, while section four concludes the paper summarising the key points that have emerged from the analysis.

\section{Theoretical Background}

Two sets of explanations have been put forward when examining the intra-urban location choices and residential decisions of people. The first - the market approach - puts emphasis on the laws of the marketplace, whereas the second - the social approach - focuses on sociological factors.

The central idea behind the market approach is that economic factors determine the location and residential choices of households and, consequently, urban spatial structure. Accordingly, observed patterns are ascribed to the decisions of rational individuals (consumers and producers) who seek to optimise their welfare, given certain restrictions and preferences (Evans 1985, Harvey J. 1996). Welfare optimisation for households is achieved when total costs are minimised or when utility is maximised. Total costs include the rent paid for the housing consumed, plus the direct and indirect costs of transport/travel. As such, their utility function depends on the quantity and qualities of housing occupied and the money and time spent travelling to work and to other activities, such as shopping, entertainment, etc.

A simple version of this market approach stresses the requirements of economic actors to minimise movement costs. Given certain simplifying assumptions with regard to the centrality of economic activity, the structure of transport costs (which vary with distance to the central market) and transportation technology, primacy is attached to the city-centre location, assumed to represent the point of greatest accessibility (O'Sullivan 2003). However, due to space scarcity, costs are higher in central locations and decrease as the distance from the centre increases. Hence, any rational location decision strikes a balance between the costs of centrality and the advantages of accessibility. On this basis, trade-off models have been developed describing the location decisions of firms and households, and in turn the patterns of urban land use (Alonso 1964, Muth 1969, Mills 1972). Location choice for firms is described as a straightforward trade-off of rent payable against distance from the centre. For households, despite being complicated by non-monetary determinants of utility (such as space and environmental considerations) the key mechanism remains intact: households trade-off transport costs to the centre against extra space or housing qualities offered elsewhere, simultaneously choosing between distance from the centre and the level of housing rent. This is why bigger households (as compared to smaller ones) choose locations at a distance from the city centre where large houses are more affordable (Evans 1973). In turn, social (and spatial) segregation at residential equilibrium is theorised with more affluent households opting to locate either at the city centre (when they value accessibility higher than housing amenities) or at peripheral locations (when they value accessibility lower than housing amenities), depending on the accessibility characteristics of the city (McDonald and McMillen 2007).

These trade-off models of the locational behaviour of firms and households provide the basis for understanding the allocation of urban space to economic activities and, in turn, explain the economic and spatial structure of the city and its dynamic properties (Anas, Arnott, and Small 1998). The monocentric form of urban structure is fundamental to these traditional urban economics theories. This describes a pattern of urban land use with service activities outbidding other uses for central locations, followed by industrial and residential uses in successive zones (Evans 1985, O' Sullivan 2003, McDonald and McMillen 2007). However, technological, economic and social changes can erode the location advantages of central accessibility, providing a new impetus to the location dynamics of specific user groups (Arvanitidis and Petrakos 2006). Taking these parameters into account (and particularly the advances in transportation and (tele)communications technology and the rise of service economy), contemporary studies (Puga and Venables 1996, Lee, Seo, and Webster 2006) have revised and extended their models in an attempt to explain decentralisation and deconcentration of certain 
economic activities. On a similar basis, other scholars (Fujita and Ogawa 1982, Mori 1997, Anas, Arnott, and Small 1998) have discussed the emergence of multiple centralities ('subcentres') and the development of the 'polycentric city'.

Drawing on the above conceptual framework, many studies have explored empirically the location and housing choices of households (see Earnhart 2002, Walker et al. 2002, Wang and Li 2004, Kim, Pagliara, and Preston 2005). These have established that such decisions are determined by considerations of accessibility costs, property prices, housing attributes and locational amenities. For instance, Kim, Pagliara, and Preston (2005) have explored the importance of house prices, neighbourhood amenities and movement costs on location preferences and found that such decisions are influenced mainly by the amount of transport costs (monetary and time-related), the local population density, the quality of schools available in the area and the property prices. These results indicate that both accessibility and neighbourhood amenities are significant in location and housing decisions.

Nevertheless, many economists do not agree with the view that location and housing choices should be premised on such narrow monetary and individualistic foundations as neoclassical economics. They have sought alternative ways to explore such choices by using an analytic focus upon non-rational behaviour and social relations or attempting to combine these with mainstream economic explanations. Within this literature, 'housing status' and 'place attachment' appear to be key concepts affecting residential location decisions.

The 'housing status' idea stems from Bourdieu's social theory. Bourdieu (1984) argues that the accumulation of not only economic but also social, cultural and symbolic capital results in socially and spatially differentiated preferences in consumption, including housing consumption. Social capital refers to resources accrual due to group membership, social relationships, and networks of support and influence. In turn, cultural capital refers to forms of education, knowledge, skills, and advantages that a person has, whereas symbolic capital refers to resources available on the basis of recognition, prestige, status or honour. The concept of housing status carries these three forms of capital into housing to add a new perspective in examining locational and housing preferences, demand and supply relations and price formation.
The amount of social, cultural and symbolic capital varies between and within places. In this sense, the qualities, relationships and ties between people have a clear spatial reference. The notions of 'place attachment' and 'neighbourhood identity' are widely used to convey this idea (Low and Altman 1992, Hall and du Gay 1996, Harvey D. 1996, Gustafson 2001). Place attachment describes the bonding developed between residents and their neighbourhood on the basis of the social, cultural and symbolic capital the latter encapsulates. This provides the individual with a feeling of belonging or participating in a community that members matter to one another, have common concerns and share a sense of identity. Identification with a neighbourhood or with a community in general, enhances the individuals' selfesteem and affords them with a sense of support and security (Taylor 1988, Altman and Low 1992, Crow 1994). It is interesting to mention here that the bonding between individuals and their neighbourhood may not be based on real, objective, ties, bur rather on perceived connections, collective memories, or subjective feelings of belonging into something that Blokland (2003) calls 'imagined communities'.

The literature identifies four basic elements that define the economic, social, cultural and symbolic capital of people, affecting their location and housing decisions: income, ethnicity, education and social status (Dekker and Bolt 2005). Income has an apparent impact on the economic capital of people, but also exerts an influence on the social relations within a neighbourhood (that is the social capital) (Fischer 1982, Campbell and Lee 1992). At its simplest, low-income residents, as compared to those of high income, are less mobile and more dependent on the social networks and resources provided locally (Campbell and Lee 1992, Lee and Campbell 1999). Closely-integrated social networks are also developed between members of ethnic or racial communities living in a neighbourhood (Bolt 2001). Such people tend to locate close to each other in order to improve information flows with regard to the institutional mechanisms of the host society (Kesteloot 1995, Pacione 1996), or to retain valued elements of their cultural heritage, such as language and religion (Boal 1996, Hugo 1996, Dunn 1998). With regard to education, it is considered to be an important factor determining the quality of cultural and social capital (Fischer 1982). The higher the education level, the broader the social networks of an individual are, at least because such activities extend beyond the place of residence (Guest 
and Wierzbicki 1999, Blokland 2000). Finally, social status signifies the symbolic capital someone attains on the basis of recognition or prestige associated with profession or social (or professional) rank, which, in turn is reflected in the location or housing choices of the individual (Dekker and Bolt 2005).

Social/spatial segregation within the above framework is analysed by the theories of place stratification and residential segregation. The place stratification model considers intra-urban space as a hierarchy of places ordered in terms of desirability and the quality of life they provide to urban dwellers (Logan 1978). Dominant social groups occupy the most desirable places, keeping other, less powered, groups (e.g. ethnic and racial minorities) at a distance. Thus, social hierarchy is reflected in space, giving rise to a place hierarchy. This place hierarchy is maintained, with varying degrees of success, through both institutional mechanisms (e.g. redlining, exclusionary zoning, etc.) and discriminatory acts on the part of the dominant groups (e.g. policing, violence against minorities, etc.).

While place stratification envisages social segregation to be imposed on certain social groups, the residential preference theory asserts that this is in fact a conscious decision by them. That is, such members prefer to reside next to each other and to remain spatially segregated, even when they have the financial means or the social status that would enable them to move elsewhere (Freeman 2000). There are many benefits to be gained due to such spatial behaviour. To newcomers, the community's social network would provide not only social and cultural support, but also other vital 'resources', such as housing and valuable information on the host institutional framework and the labour market (Hagan 1998). To all other members, the community represents the stronghold of their own cultural identity; in a sense it constitutes a specific, local, social public good.

The propositions of the social approach to residential preferences have been examined empirically by a number of studies. Gram-Hanssen and Bech-Danielsen (2004) have explored the cultural meanings of home in Denmark to demonstrate that houses and neighbourhoods are associated with symbolic values which differ from place to place and affect the residential choices of people. From a similar perspective, Marvell (2004) studied explicit meanings with reference to a new development area in Swindon (UK), where private housing for upper-class people had been produced in a way heavily influenced by social status considerations.
With regard to other soft or intangible factors that affect the locational and housing behaviour of households, and hence the residential intra-urban patterns that develop, the literature has drawn attention to issues such as tastes, lifestyle and image (Ley 1986, Murie 1998, Galster 2001, Aero 2006, Kauko 2006).

What becomes apparent from the above discussion is that location and housing decisions and the resulting residential patterns can be explained by both market and social approaches. A number of empirical studies have attempted to assess the validity of the arguments set forth, and on these grounds to evaluate the explanatory power of the approaches. Although much work is still to be done in this area, we could conclude that traditional economic factors (such as, land prices, accessibility, etc.) play a substantial role in the households' residential decisions, but in order to account for the great variety in the residential structures observed within urban space, such arguments need to be enriched with soft determinants of housing choices (such as social capital, status, etc.).

\section{Methodology, Data and Analysis}

Due to serious external security concerns, Greece allocates substantial human and material resources to defence (Kollias 1995, Kollias and Paleologou 2003). Both in terms of the defence burden (military spending as a share of GDP) as well as in terms of human capital committed to defence, Greece invariably surpasses the corresponding NATO averages (see Table 1). It can reasonably be argued that, irrespective of the reasons for maintaining such a comparatively large proportion of the population in the armed forces (conscripts and professionals), this probably exerts an impact both on the labour market as well as on regional economies and societies given the dispersion of military facilities throughout Greece. Yet, despite the large literature, as comprehensively summarized by Brauer (2002), no attention has been paid to such aspects when it comes to the Greek defence sector. Thus, to the best of our knowledge, there are no previous studies examining the locational and residential aspects of AFP households in Greece. In light of this, the current paper constitutes a first attempt to do so, using the medium-size city of Volos as a case study. The choice of this particular city is due to the fact that a number of important military facilities are located either within or in the vicinity of the city. These include an air force base, a marine unit, the army aviation 


\begin{tabular}{llcccccc} 
& & 1985 & 1990 & 1995 & $\mathbf{2 0 0 0}$ & $\mathbf{2 0 0 5}$ & $\mathbf{2 0 0 7}$ \\
\hline Military spending & Greece & 7.0 & 4.6 & 3.8 & 4.3 & 3.4 & 3.3 \\
(\% of GDP) & NATO & 3.5 & 3.1 & 2.4 & 2.1 & 2.5 & 2.5 \\
\hline Armed forces personnel & Greece & 5.7 & 5.3 & 5.3 & 4.8 & 3.0 & 2.9 \\
(\% of labour force) & NATO & 2.7 & 2.5 & 1.9 & 1.6 & 1.2 & 1.2 \\
\hline
\end{tabular}

Sources: SIPRI and NATO

Table 1: The Greek defence sector 1985-2007

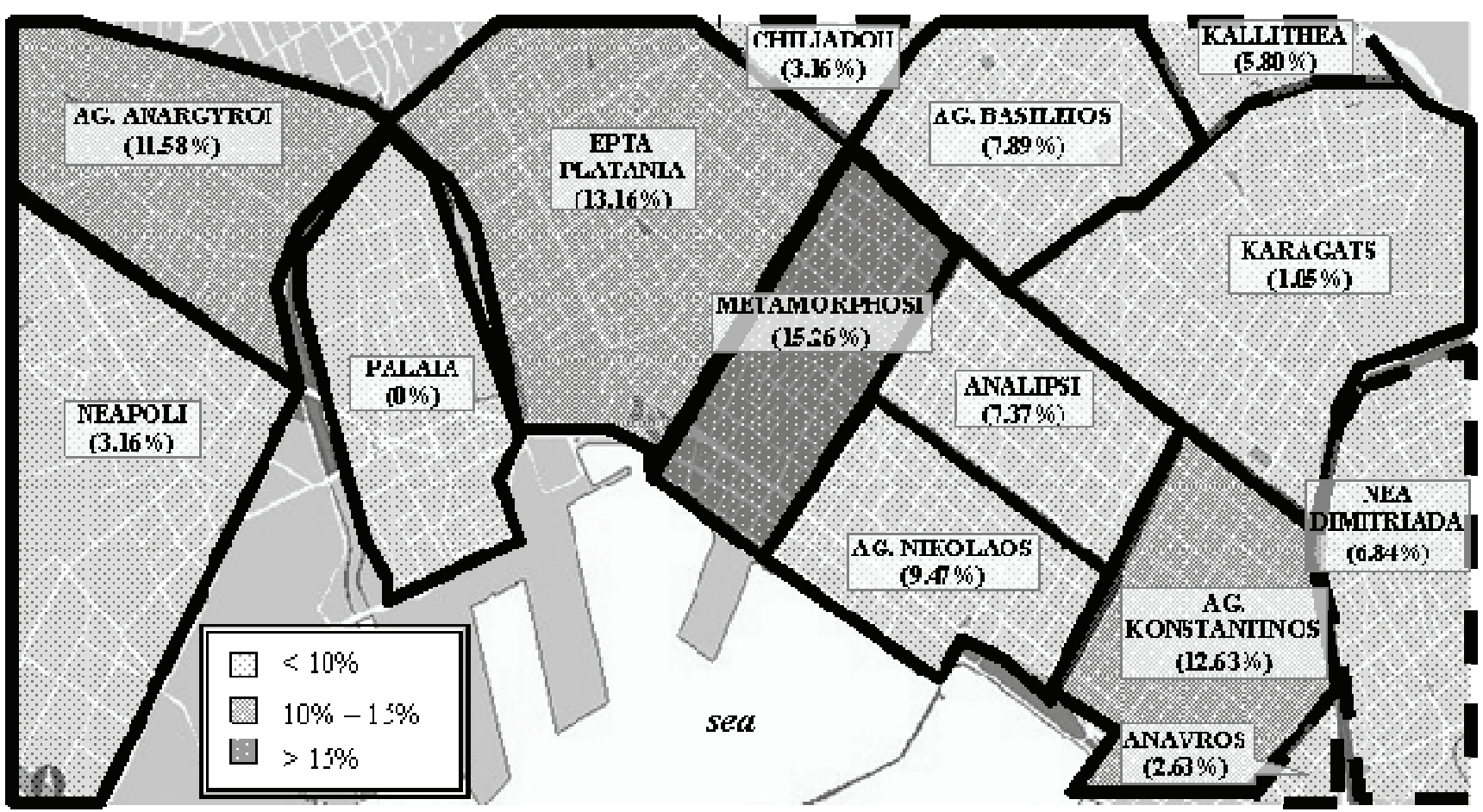

Source: own construction

Map 1: Spatial distribution of AFP in Volos (\% of households)

brigade headquarters, the army's Main Battle Tank (MBT) maintenance industrial plant, as well as some secondary facilities. As a result the city offers residence to quite a few military households.

The study starts by identifying the intra-urban spatial distribution of AFP households and comparing this with the overall pattern of residential location evident in the city. Following this, an attempt is made to explain the observed AFP distribution with reference to the economic determinants of location choice (that is, minimization of transport costs) or other factors related to the social or professional characteristics of the group.

Due to the lack of official data on the spatial distribution of any professional group within the city, the study obtained such information through primary research. Thus, the location and residential characteristics of AFP were acquired with the use of a questionnaire survey. This was conducted in December 2006 and was addressed to AFP residing in the city of Volos. The particular information sought was the exact location of residence and tenure status of AFP, as well as their rank in the military hierarchy ${ }^{2}$, their marital status and the size of their household. The data analyzed herein was collected from 190 valid responses out of a total population of 587 AFP that in 2006 resided in Volos. This number exceeds the projected sample size of 186 , which is the minimum required (at a $90 \%$ confidence level) given the total population in question. The sample size of our survey corresponds to a $4.9 \%$ margin of error for the specified (90\%) confidence level.

The pattern of residential location for the whole city is reflected on the building (construction) activity that takes place in each neighbourhood. The study acquired such data from the municipality's Urban Planning Directorate. This refers to 561 new buildings (consisting of 5,266

${ }^{2}$ For national security reasons this dimension could not be incorporated into the analysis that is presented here. For the same reason, certain information on the specific location of AFP has been omitted. 


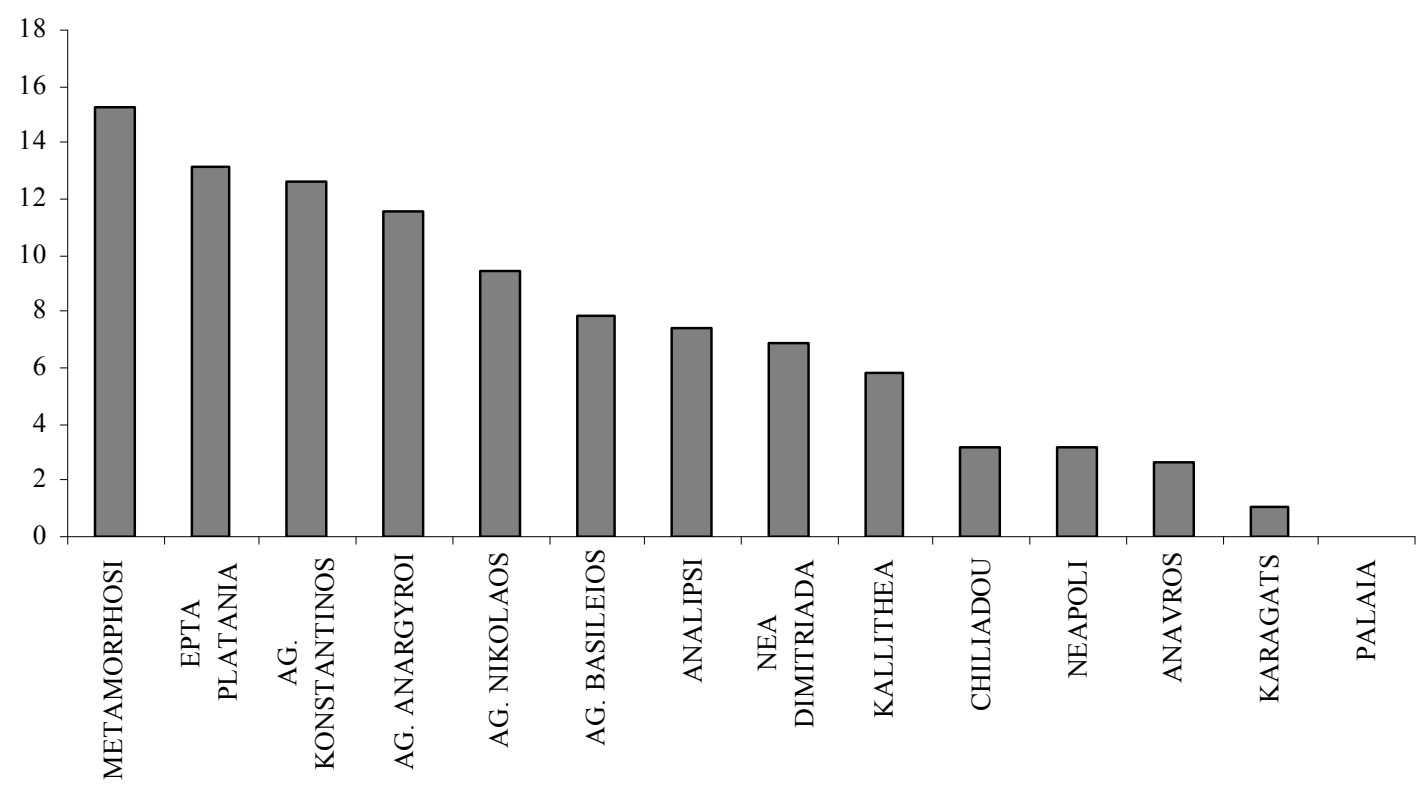

Figure 1: Spatial distribution of the AFPs in Volos (\% of households)

apartments on about 400,000 sqm space) constructed in Volos during the period 1999 to 2004. The reason the analysis was restricted to this time frame is due to the high distortions in property development that occurred both before 1998 and after 2005. In particular, there had been a remarkably low level of construction activity between 1992 and 1998, something which has been attributed to the redirection of household investment from housing to the stock market (Arvanitidis and Skouras 2008). In turn, construction activity rocketed between 2005-2007 due to governmental announcements (and subsequent policies put forward) that taxes related to both property transaction and building construction would be substantially increased in the following years (Arvanitidis and Skouras 2008).

Map 1 presents the spatial distribution of the AFP households in Volos. Neighbourhoods are ranked according to the percentage of AFPs they house and the results are provided in Figure 1. As can be seen, AFP households are rather dispersed all over the urban area and there seems to be no high spatial clustering in the city. However, a slight preference for central areas is also identifiable. About $17 \%$ of the AFPs take up residence in the traditional urban centre (that is the Ag. Nikolaos and the Analipsi areas), whereas about $15 \%$ and $13 \%$ are located in Metamorphosi and Epta Platania, respectively, which together constitute the extended city-centre (Arvanitidis and Skouras 2008). Overall, we observe that about half of the AFP households (45.26\%) are located in central areas. High percentages of AFPs are also found in
Ag. Konstantinos (about 13\%), the most prestigious neighbourhood of the city and which houses people of high socioeconomic status, and in Ag. Anargyroi in the western side of the city, across Larisis Street, which is the main road connecting Volos with two of the main military facilities located outside of the city. In general, these six neighbourhoods (i.e. Ag. Nikolaos, Analipsi, Metamorphosi, Epta Platania, Ag. Konstantinos and Ag. Anargyroi) accommodate about $70 \%$ of AFP households. The rest of AFP (30\%) take up residence in the remaining neighbourhoods of Neapoli, Anavros, Nea Dimitriada, Karagats, Ag. Basileios, Chiliadou and Kallithea.

Given the findings described above, we can tentatively conclude that there is no particular characteristic or cultural element related to AFP that may lead to some kind of high residential clustering for this specific professional group. To put it differently, there is no evidence that attributes such as professional status, image, lifestyle or common identity give rise to spatial isolation and clustering of AFP. Consequently we argue that the location and housing decisions of AFP, and the resulting residential patterns, are determined by economic determinants rather than social factors.

An interesting picture emerges when we compare the spatial distribution of AFP with the overall pattern of building activity that took place in the previous years (Table 2 and Figure 2). It seems that AFP tend to locate in those areas where increased construction activity is evident or where new housing stock is provided. This is 


\begin{tabular}{|c|c|c|c|}
\hline Area & $\begin{array}{l}\text { Spatial distribution of AFP } \\
\text { (\% of households in 2006) } \\
\text { (1) }\end{array}$ & $\begin{array}{c}\text { Building activity } \\
\text { (\% of total construction permits } \\
\text { during 1999-2004) } \\
\text { (2) }\end{array}$ & $\begin{array}{l}\text { Difference } \\
\text { between } \\
\text { (1)-(2) }\end{array}$ \\
\hline AG. NIKOLAOS & 9.47 & 3.84 & 5.63 \\
\hline EPTA PLATANIA & 13.16 & 7.69 & 5.47 \\
\hline AG. ANARGYROI & 11.58 & 6.73 & 4.85 \\
\hline AG. BASILEIOS & 7.89 & 5.45 & 2.44 \\
\hline KALLITHEA & 5.80 & 5.17 & 0.63 \\
\hline METAMORPHOSI & 15.26 & 14.74 & 0.52 \\
\hline ANALIPSI & 7.37 & 8.33 & -0.96 \\
\hline ANAVROS & 2.63 & 3.84 & -1.21 \\
\hline AG. KONSTANTINOS & 12.63 & 14.10 & -1.47 \\
\hline NEA DIMITRIADA & 6.84 & 8.65 & -1.81 \\
\hline CHILIADOU & 3.16 & 5.13 & -1.97 \\
\hline PALAIA & 0.00 & 2.56 & -2.56 \\
\hline NEAPOLI & 3.16 & 5.76 & -2.60 \\
\hline KARAGATS & 1.05 & 8.01 & -6.96 \\
\hline
\end{tabular}

Source: own construction

Table 2: AFP spatial distribution and building activity in Volos

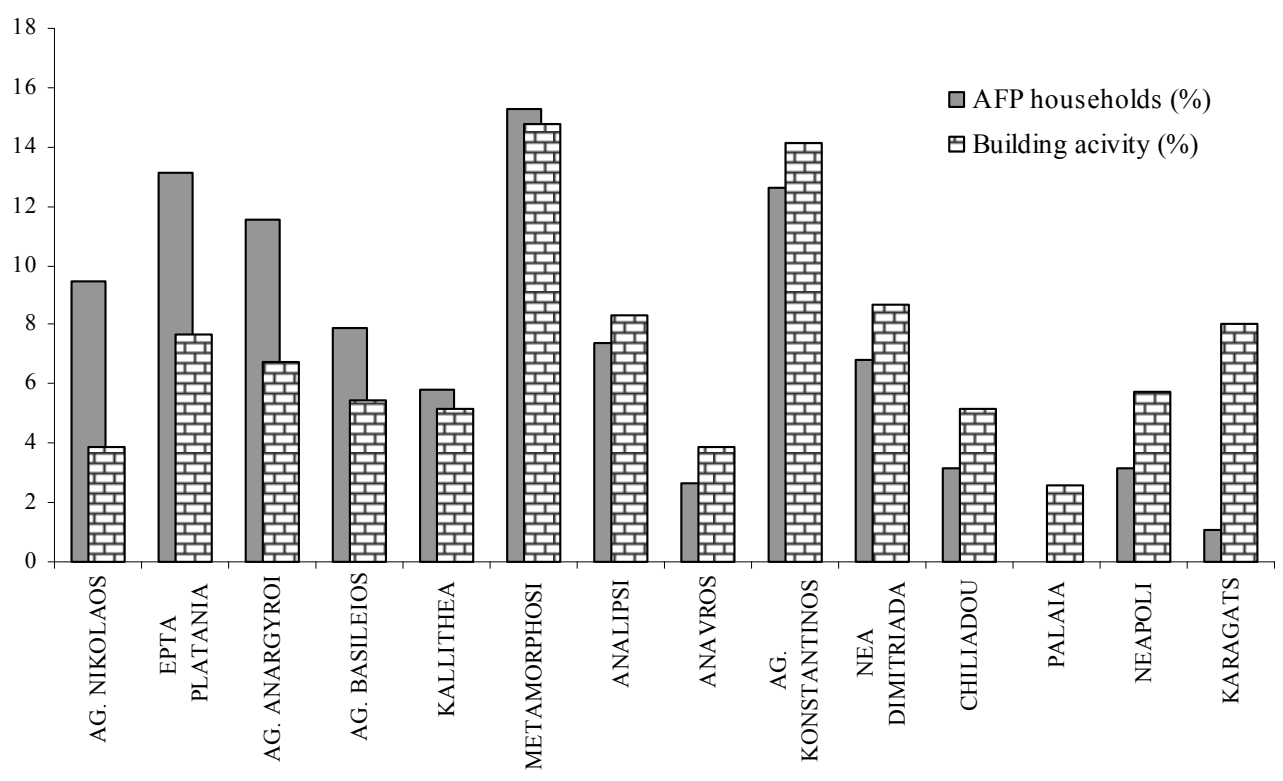

Source: own construction

Figure 2: AFP spatial distribution and building activity in Volos

verified by the high correlation coefficient between the two variables, which is equal to 0.67 .

The percentage of AFP households located in a neighbourhood, as compared to the construction activity the neighbourhood has experienced, is higher in the areas of Ag. Nikolaos (that is, the city-centre), Epta Platania (that is, the extended city-centre), Ag. Anargyroi and Ag. Basileios, and it is about the same in Analipsi (again, the city-centre), Metamorphosi (the extended city-centre) and
Kallithea (Table 2 and Figure 2). The peripheral neighbourhoods of Karagats, Neapoli, Chiliadou, Nea Dimitriada, Anavros, Ag. Konstantinos and Palaia have attracted the attention of developers but not of the AFP households, at least to a comparable degree. Overall, we verify the pattern identified previously: the central locations seem to exert an attraction to many AFP households, though there are some peripheral neighbourhoods (Ag. Anargyroi and Ag. Basileios) where 
AFPs locate, despite the low housing development these areas have exhibited.

The examination of AFP's tenure status reveals another important aspect of their housing preferences. Of the 190 people surveyed, more than three quarters $(77.37 \%)$ live in rented housing. The rest, $22.63 \%$, are owners-occupiers, indicating an owner-occupation rate for AFP which is much lower than that of the whole Greek population, standing firmly above $80 \%$ (Eurostat 2004, EMF 2007). This low incidence of AFP owner-occupation can be justified on the basis of established professional practices and the consequent features of servicemen's lives. Due to organisational and operational reasons all military personnel in Greece have to serve in different bases and so they are relocated every three to four years to different regions across the country. This results in a highly mobile lifestyle discouraging home ownership and establishing rented housing as the normal tenure practice among AFP.

$$
\begin{aligned}
& \text { Single persons sharing } \\
& \begin{array}{|l|}
\text { Married Couples } \\
\hline \text { (both working) }
\end{array} \\
& \mid \begin{array}{c|}
\text { Single Persons } \\
\text { (one member working) }
\end{array} \\
& \mid \begin{array}{|}
\text { Married Couples with childrert } \\
\text { (Both parents working) } \\
\text { Married Couples with children } \\
\text { (one member working) }
\end{array}
\end{aligned}
$$

City centre

Edge of city

Source: adapted from Evans (1973)

Figure 3: Family type and intra-urban location choices

When it comes to the factors giving rise to the above pattern of AFP spatial distribution, conventional urban economics suggest that household size plays an important role. In particular, it is argued that the larger the family, the farther it resides from the city centre (see discussion in Section 2; also portrayed in Figure 3). We examined whether this is the case for AFP in Volos. Table 3 presents the household structure of AFP that participated in the survey. As it can be seen most of these are small households (62.6\%), that is, married couples with no children or single persons, whereas only $37 \%$ are larger families comprising two spouses and children. This is not something unexpected, since operational military units, such as those located in the greater Volos area, are staffed largely with personnel which is young and with no family commitments. Such servicemen are expected to show a preference for central locations. Apparently, this is because (as informal discussions with the participants revealed) they highly value specific urban facilities which are available in the city-centre (for entertainment, shopping, etc.), but are not willing to incur the high travel costs (monetary and time related) attached to peripheral locations. As such, they settle for smaller houses of higher rent (per sqm) which are available in the centre, instead of larger, lower-rented (per sqm) properties in the periphery.

\begin{tabular}{lcc}
\hline Household structure & $\begin{array}{c}\text { No. of } \\
\text { households }\end{array}$ & Percentage \\
\hline $\begin{array}{l}\text { Married couples with } \\
\text { children }\end{array}$ & 71 & 37.4 \\
$\begin{array}{l}\text { Married couples without } \\
\text { children }\end{array}$ & 77 & 40.5 \\
Single persons & 42 & 22.1 \\
\hline
\end{tabular}

Source: own construction

Table 3: Household structure of AFP living in Volos

Indeed, the aforementioned trend is verified when the spatial distribution of both the small and large households of the AFPs is examined (see Table 4). It becomes evident that small households prefer the central areas of Ag. Nikolaos and Analipsi (traditional city-centre) or Metamorphosi (extended city-centre) to take up residence, whereas the peripheral neighbourhoods of Kallithea, Chiliadou and Ag. Basileios house mainly large AFP households. Neapoli and Ag. Anargyroi are the only peripheral neighbourhoods that accommodate high percentages of small households. In fact, in Neapoli all AFP households are small, whereas in Ag. Anargyroi small households are 2.14 times higher than large ones. We presume that this is due to two reasons. First because these areas are highly accessible since they in front of Larisis Street, which is the road that connects Volos with those military facilities located outside the city, and second, because they are rather degraded areas with cheap housing stock, accommodating mostly low-income servicemen.

What becomes apparent from the discussion up to now is that accessibility issues and the associated costs (in terms of both money and time spent on travelling) play an important role in the location decisions of AFP in Volos. A considerable part of these expenses concerns everyday travelling from home to work and back, especially given the fact that 'work' (i.e. most of the 


\begin{tabular}{lcccc}
\hline Area & $\begin{array}{c}\text { Small } \\
\text { households (\%) } \\
\text { (1) }\end{array}$ & $\begin{array}{c}\text { Large } \\
\text { households (\%) } \\
(\mathbf{2})\end{array}$ & $\begin{array}{c}\text { Difference } \\
(\mathbf{1})-(\mathbf{2})\end{array}$ & $\begin{array}{c}\text { Ratio } \\
(\mathbf{1}) /(\mathbf{2})\end{array}$ \\
\hline NEAPOLI & 100.00 & 0.00 & 100.00 & - \\
(2)/(1)
\end{tabular}

Source: own construction

Table 4: AFP's household size and spatial distribution

military facilities) is located outside of the city of Volos. This home-to-work trip consists of two routes: one from home to the bus-stop where the military bus collects AFP, and another from the bus-stop to the military facility. The latter route is common to all AFP at the expense of the Hellenic Armed Forces. Thus, it is the former travel costs that burden each one of the servicemen individually and should affect their location decision. In other words, we expect AFP house location to be as close as possible to these bus stops. This indeed seems to be the case. In fact, 131 out of 190 AFP households (68.95\%) are located within two blocks of the closest bus-stop.

\section{Concluding Remarks}

The paper set out to examine the locational and residential decisions of Greek military households. To achieve this, primary data were collected by means of a questionnaire survey addressed to a number of servicemen located in Volos, a medium-sized Greek city with a number of military facilities located in the area. On the basis of the preceding analysis, a number of tentative conclusions may be reached.

First, military households are rather dispersed all over the urban areas and there seems to be no considerable spatial concentrations for this specific professional group. On these grounds, we assume that that there are no strong social, cultural or symbolic attributes (such as professional image, status or common identity) bonding these people that may lead to a kind of spatial clustering and isolation. Put differently, the location and housing decisions of the military households, and the resulting residential patterns, are determined by conventional urban economic determinants rather than specific sociocultural factors which are particularly relevant to this professional group.

Second, military households seem to show a slight preference for central locations. This is mainly due to the fact that the majority of AFP households are small, comprised of one to two persons. In accordance with arguments put by conventional urban economics, they highly value specific urban facilities which are available in the city-centre (e.g. entertainment, shopping, etc.) and are not willing to pay the high travel costs (measured in terms of both money and time spent) associated with living in peripheral locations. As such, they settle for smaller houses which are available in the centre, instead of larger properties in the periphery.

Third, general accessibility issues and the associated travel costs play an important role in AFP location decisions. This is why more than two thirds of the military households examined are located close to the bus-stops from where AFP are collected in order to be transferred to the respective military facilities where they serve.

Finally, in terms of their residential attributes, the households of servicemen seem to show a preference for new buildings, since they tend to locate in those areas where increased construction activity is evident or where new housing stock has been provided. In addition, their highly mobile lifestyle seems to discourage home ownership and to establish rented housing as a typical practice among them.

Concluding this paper, it must be pointed out that the current research is preliminary in its nature. It constitutes 
a first attempt to shed light on the effects residential decisions of military households have on the spatial structure and housing market of the cities that accommodate them. Further research is needed where additional case studies would scrutinise such patterns to verify and refine the conclusions drawn here. $[$.

\section{References}

Aero, T. 2006. Residential Choice from a Lifestyle Perspective. Housing, Theory and Society 23 (2): 109-130.

Alonso, W. 1964. Location and Land Use: Towards a General Theory of Land Rent. Cambridge: Harvard University Press.

Altman, I. and Low, S. M. 1992. Place Attachment. New York: Plenum Press.

Anas, A., Arnott, R. and Small, K. A. 1998. Urban Spatial Structure. Journal of Economic Literature 36 (3): 1426-1464.

Andersson, L., Lundberg, J. and Sjostrom, M. 2007. Regional Effects of Military Base Closures: the Case of Sweden. Defence and Peace Economics 18 (1): 87-97.

Arvanitidis, P. and Petrakos, G. 2006. Understanding Economic Change in the Cities: A Review of Evidence and Theory. European Spatial Research and Policy 13 (2): 97-122.

Arvanitidis, P. and Skouras, D. 2008. Urban Location and Housing Values: exploring the links in the city of Volos. Technika Chronika 28 (1): 31-41.

Asteris, M., Grainger, J., Clark, D. and Jaffry, S. 2007. Analysing Defence Dependency: the Impact of the Royal Navy on a Sub-Regional Economy. Defence and Peace Economics 18 (1): 53-73.

Blokland, T. 2000. Unravelling three of a kind: cohesion, community and solidarity. Netherlands Journal of Social Sciences 36 (1): 56-70.

Blokland, T. 2003. Urban Bonds. Cambridge: Polity Press.

Boal, F. W. 1996. Immigration and ethnicity in the urban Milieu. In EthniCity, Geographic Perspectives on Ethnic Change in Modern Cities, edited by C. C. Roseman, H. D. Laux and G. Thieme, 283-304. Maryland: Rowman and Littlefield.

Bolt, G. 2001. Wooncarrieres van Turken en Marokkanen in Ruimtelijk Perspectief. Utrecht: Faculteit Ruimtelijke Wetenschappen.

Bourdieu, P. 1984. Distinction: A Social Critique of the Judgement of Taste. London: Routledge.

Braddon, D. 1995. The Regional Impact of Defense Expenditure. In Handbook of Defense Economics Vol. 1, edited by K. Hartley and T. Sandler, 491-521. Amsterdam: Elsevier.

Brauer, J. 2002. Survey and review of the defence economics literature on Greece and Turkey: what have we learned? Defence and Peace Economics 13 (2): 85-107

Brauer, J. and Hartley K. eds. 2000. The Economics of Regional Security: NATO, the Mediterranean and Southern Africa. Amsterdam: Harwood.

Brauer, J. and Dunne, P. eds. 2002. Arming the South: The Economics of Military Expenditure, Arms Production and Arms Trade in Developing Countries. Houndmills: Palgrave.

Campbell, K. E. and Lee, B. E. 1992. Sources of personal neighbor networks: social integration, need or time. Social Forces 70: 1077-1100.

Crow, D. 1994. My friends in low places: building identity for place and community. Environment and Planning D 12: 403-419.
Dekker, K. and Bolt, G. 2005. Social cohesion in post war estates in the Netherlands: differences between socioeconomic and ethnic groups. Urban Studies 42 (13): 2447-2470.

Dunn, K. M. 1998. Rethinking ethnic concentration: the case of Cabramatta, Sydney. Urban Studies 35 (3): 503-527.

Earnhart, D. 2002. Combining Revealed and Stated Data to Examine Housing Decisions Using Discrete Choice Analysis. Journal of Urban Economics 51: 143-169.

EMF 2007. Hypostat 2007: A Review of Europe's Mortgage and Housing Markets. Brussels: European Mortgage Federation.

Eurostat 2004. Trends in Households in the European Union: 19952025. Luxembourg: Eurostat.

Evans, A. W. 1973. The Economics of Residential Location. London: Macmillan.

Evans, A. W. 1985. Urban Economics, An Introduction. Oxford: Blackwell.

Fischer, C. S. 1982. To Dwell among Friends: Personal Networks in Town and City. Chicago, IL: University of Chicago Press.

Freeman, L. 2000. Minority housing segregation: A test of three perspectives. Journal of Urban Affairs 22 (1): 15-35.

Fujita, M. and Ogawa, H. 1982. Multiple equilibria and structural transition of non-monocentric urban configurations. Regional Science and Urban Economics 12: 61-196.

Galster, G. 2001. On the nature of neighbourhood. Urban studies 38 (12): 2111-2124.

Gram-Hanssen, K., and Bech-Danielsen, C. 2004. House, home and identity from a consumption perspective. Housing, Theory and Society 21 (1): 17-26.

Guest, A. and Wierzbicki, S. 1999. Social ties at the neighbourhood level: two decades of Gss evidence. Urban Affairs Review 35: 92-111.

Gustafson, P. 2001. Meanings of place: Everyday experience and theoretical conceptualizations. Journal of Environmental Psychology 21: 5-16.

Hagan, J. 1998. Social Networks, Gender and Immigrant Incorporation: Resources and Constraints. American Sociological Review 63: 55-67.

Hall, S. and du Gay, P. eds. 1996. Questions of Cultural Identity. London: Sage

Hartley, K. and Sandler, T. eds. 1990. The Economics of Defense Spending: An International Survey. London: Routledge.

Hartley, K. and Sandler, T. eds. 1995. Handbook of Defence Economics, Vol. 1. Amsterdam: Elsevier.

Harvey, D. 1996. Justice, Nature and the Geography of Difference. Oxford: Blackwell.

Harvey, J. 1996. Urban Land Economics, $4^{\text {th }}$ ed. London: Macmillan.

Hooker, M. and Knetter, M. 2001. Measuring the Economic Effects of Military-base Closures. Economic Inquiry 39 (4): 583-598

Hugo, G. J. 1996. Diversity down under: the changing ethnic mosaic of Sydney and Melbourne. In EthniCity, Geographic EthniCity, Geographic Perspectives on Ethnic Change in Modern Cities, edited by C. C. Roseman, H. D. Laux and G. Thieme, 102-134. Maryland: Rowman and Littlefield.

Kauko, T. J. 2006. Expressions of Housing Consumer Preferences: Proposition for a Research Agenda. Housing Theory and Society 23 (2): 92-108.

Kesteloot, C. 1995. The creation of socio-spatial marginalization in Brussels: a tale of flexibility, geographical competition and guestworker 
neighbourhoods. In Europe at the margins: New Mosaics of Inequality, edited by D. Sadler and C. Hadjimichalis, 82-99. Chichester: Wiley.

Kim, J-H., Pagliara, F. and Preston, J. 2005. The Intention to Move and Residential Location Choice Behaviour. Urban Studies 42(9): 1621-1636.

Kollias, C. 1995. Country Survey VII: Military Spending in Greece. Defence and Peace Economics 6(4): 305-319.

Kollias, C. and Paleologou, S. M. 2003. Domestic political and external security determinants of the demand for Greek military expenditure. Defence and Peace Economics 14(6): 437-445.

Lee, B. A. and Campbell, K. E. 1999. Neighbor networks of black and white Americans. in Networks in the Global Village: Life in Contemporary Communities, edited by B. Wellman, 119-146. Boulder, CO: Westview.

Lee, S., Seo, J. G. and Webster, C. 2006. The Decentralising Metropolis: Economic Diversity and Commuting in the US Suburbs. Urban Studies 43 (13): 2525-2549.

Ley, D. 1986. Alternative explanations for inner-city gentrification: a Canadian assessment. Annals of the Association of American Geographers 76: 521-535.

Logan, J. R. 1978. Growth, politics and the stratification of places. American Journal of Sociology 84: 404-416.

Low, S. and Altman, I. 1992. Place attachment: A conceptual inquiry. In Place attachment, edited by I. Altman and S. Low, 1-12. New York: Plenum.

Marvell, A. 2004. Making of the 'Meads: suburban development and identity. Geography 89 (1): 50-57.

McDonald, J. F. and McMillen, D. P. 2007. Urban Economics and Real Estate, Theory and Policy. Oxford: Blackwell.

Mills, E. S. 1972. Urban Economics. Glenview: Scott, Foresman and Company.

Mori, T. 1997. A modeling of megalopolis formation: the maturing of city systems. Journal of Urban Economics 42: 133-157.

Murie, A. 1998. Uncertainty and fragmentation: social aspects of housing studies. In Housing in Europe: analysing patchworks, edited by A. J. H. Smets and T. Traerup, 21-32. Utrecht/Horsholm: Utrecht University / Danish Building Research Institute.

Muth, R. 1969. Cities and Housing: The Spatial Pattern of Urban Residential Land Use. Chicago: University of Chicago Press.

O'Sullivan, A. 2003. Urban Economics, $5^{\text {th }}$ ed. New York: McGraw Hill.

Pacione, M. 1996. Ethnic segregation in the European city. Geography 81: 120-132.

Poppert, P. E. and Herzog, H. W. 2003. Force Reduction, Base Closure, and the Indirect Effects of Military Installations on Local Employment Growth. Journal of Regional Science 43 (3): 459-482

Puga, D. and Venables, T. 1996. The spread of industry: spatial agglomeration in economic development. Journal of the Japanese and International Economies 10 (4): 440-464

Sandler, T. and Hartley, K. eds. 2007. Handbook of Defence Economics, Vol 2. Amsterdam: North Holland

Taylor, R. B. 1988. Human Territorial Functioning. Cambridge: Cambridge University Press.

Walker, B., Marsh, A., Wardman, M. and Niner, P. 2002. Modelling tenants' choices in the public rented sector: A stated preference approach. Urban Studies 39 (4): 665-688.

Wang, D. and Li, S. M. 2004. Housing Preferences in a Transitional Housing System: The Case of Beijing, China. Environment and Planning A 36: 69-87. 